\title{
Academic medicine responds to the opioid crisis
}

John Prescott MD ${ }^{1}$

\section{Author Affiliation:}

1. Association of American Medical Colleges, Washington DC

The author has no financial disclosures to declare and no conflicts of interest to report.

\section{Corresponding Author}

John Prescott MD

Association of American Medical Colleges

Washington DC

Email: jprescott@aamc.org

\begin{abstract}
Opioid dependence has devastated communities across the nation particularly in rural states and academic medicine has responded in a variety of ways. Through its tripartite mission of education, research, and clinical care, creative solutions are being implanted. Medical schools and teaching hospitals are partnering with public health and law enforcement agencies, as well as local healthcare providers to address the clinical, social, and rehabilitative challenges. Academic medicine continues to adapt to the needs of the nation and teach, train, and prepare the next generation of physicians to be at their best when things are at their worst.
\end{abstract}

\section{Keywords}

Opioids, academic medicine, medical education, crisis 
Opioid dependence has devastated communities across the country, hitting West Virginia especially hard. Heroin overdoses in the state have quadrupled in the last ten years, and last year, this crisis killed more than 700 individuals in the state - that is two people every day who are losing their battle with substance misuse. As an emergency medicine physician in WV for more than 20 years, I saw the devastating effects of addiction and overdoses and the impact they had on individuals, their families, and their communities.

It is clear that while this epidemic is the result of many factors, including well-meaning physicians adapting to society's emphasis on pain becoming the "fifth vital sign", medical schools must address this crisis head on as part of their ongoing commitment to meeting the changing needs of their communities.

Through their tripartite mission of education, research, and clinical care, the nation's medical schools and teaching hospitals are actively responding to this public health crisis and preparing the next generation of health care professionals to address the epidemic. Medical schools, including the Joan C. Edwards School of Medicine, are expanding upon and updating clinical and classroom curricula to include pain management and substance abuse treatment.

As a result, coursework in patient pain management competencies is being enhanced. This includes effective communication skills that aid future physicians in learning how to have conversations with patients about pain and potential pain management therapies, including nonpharmaceutical alternatives. In other scenarios, physicians may need to have candid conversations with patients who may be suspected of misusing opioids. These communication skills will prepare physicians to address opioid use and abuse directly and serve as foundations for building effective relationships with all patients.

While students are exposed to this material through multiple modalities in medical school, to be maximally effective, such experiences must also be reinforced throughout the continuum of medical education. Just last fall, Marshall hosted an Opioid Prescribing Workshop as part of Family Medicine Grand Rounds that covered a variety of topics related to pain management and opioid abuse.

Medical education is constantly changing to incorporate groundbreaking research into treatments for chronic pain, substance abuse disorders, and other related topics. Additionally, physicians and residents at teaching hospitals across the country put this research into practice to advance efforts to prevent, identify, and treat substance abuse.

But we cannot, and should not attempt to do this alone. Addressing the opioid epidemic and other public health crises requires engaging with our communities, other health and related professions, and the public sector. Medical schools and teaching hospitals are hosting public education programs on the dangers of prescription drug and other substance abuse, working with local law enforcement and other health professionals in their communities to provide recovery and rehabilitation for those suffering from addiction, and engaging with local, state, and federal governments to prevent and combat addiction. 
Last September, with support from a grant from the Substance Abuse and Mental Health Services Administration (SAMHSA), Marshall embarked on a collaborative effort between its departments of Psychology, Social Work, Counseling, Public Health, Nursing and Physical Therapy, the School of Pharmacy, and the Joan C. Edwards School of Medicine to educate future professionals on the skills needed to deliver the Screening, Brief Interventions and Referral for Treatment (SBIRT) training. SBIRT training involves using evidence-based practices to identify, reduce, and prevent problematic use, abuse, and dependence on alcohol and illicit drugs.

In October, 2015, the deans of West Virginia's two medical schools, Marshall University and West Virginia University, participated in a town hall with President Obama, community leaders, law enforcement, and health care professionals to discuss the impact of substance abuse and announce new efforts to address such issues.

As part of that meeting, the Association of American Medical Colleges (AAMC) pledged to share professional guidance and best practices to better educate the future health care workforce about opioid misuse and substance use disorders. As medical education, like medicine itself, needs to be evidence-based, the AAMC is committed to facilitating opportunities for our members to learn from one another about the most effective best practices and most promising breakthroughs. These innovations in education and care, successful public education and engagement campaigns, and influential research put medical schools and teaching hospitals in position to lead the community and improve care, education, and research throughout the country.

As the academic medicine community has done with HIV/AIDS, Ebola, and other public health issues, we will continue to respond to the opioid epidemic. We will continue to teach, train, and prepare the next generation of physicians and other health professionals to be at their best when things are at their worst.

John E. Prescott, MD

Chief Academic Officer, AAMC

Dean, WVU School of Medicine, 2004-08 